\title{
Comparison of two split-window methods for retrieving land surface temperature from MODIS data
}

\author{
Shaohua Zhao ${ }^{1,2,3, *}$, Qiming Qin ${ }^{1}$, Yonghui Yang ${ }^{2}$, Yujiu Xiong ${ }^{3}$ and Guoyu Qiu ${ }^{3}$ \\ ${ }^{1}$ Institute of Remote Sensing and Geographic Information System, Peking University, Beijing 100 871, China. \\ ${ }^{2}$ Center for Agricultural Resources Research, Institute of Genetic and Developmental Biology, Chinese \\ Academy of Sciences, Shijiazhuang 050 021, China. \\ ${ }^{3}$ State Key Laboratory of Earth Surface Processes and Resource Ecology, College of Resources Science \\ and Technology, Beijing Normal University, Beijing 100 875, China. \\ *e-mail: zshyytt@126.com
}

Land surface temperature (LST) is a key parameter in environment and earth science study, especially for monitoring drought. The objective of this work is a comparison of two split-window methods: Mao method and Sobrino method, for retrieving LST using MODIS (Moderate-resolution Imaging Spectroradiometer) data in North China Plain. The results show that the max, min and mean errors of Mao method are $1.33 \mathrm{~K}, 1.54 \mathrm{~K}$ and $0.13 \mathrm{~K}$ lower than the standard LST product respectively; while those of Sobrino method are $0.73 \mathrm{~K}, 1.46 \mathrm{~K}$ and $1.50 \mathrm{~K}$ higher than the standard respectively. Validation of the two methods using LST product based on weather stations shows a good agreement between the standard and Sobrino method, with RMSE of 1.17 K, whereas RMSE of Mao method is $1.85 \mathrm{~K}$. Finally, the study introduces the Sobmao method, which is based on Sobrino method but simplifies the estimation of atmospheric water vapour content using Mao method. The Sobmao method has almost the same accuracy with Sobrino method. With high accuracy and simplification of water vapour content estimation, the Sobmao method is recommendable in LST inversion for good application in Ningxia region, the northwest China, with mean error of $0.33 \mathrm{~K}$ and the RMSE value of $0.91 \mathrm{~K}$.

\section{Introduction}

Land surface temperature (LST) is a good indicator of energy and water balance on the interface between the atmosphere and land. It has attracted much attention in recent decades owing to a large scale temperature information requirement in environmental and earth sciences, for example, in drought monitoring. One of the most important potential applications of LST retrieved from satellite data is in the validation and improvement of global meteorological prediction models after proper aggregation and parameterization (Price 1982; Diak and Whipple 1993). The inversion of LST from satellite data requires correction for atmosphere-induced effects, mainly the absorption and emission of atmospheric water vapour and surface emissivity, which can be significantly lower than unity and varies spatially with surface cover and cover type (Coll et al 2005). As for MODIS data, LST retrieval is performed mainly through the application of split-window technique. Several split-window algorithms have been developed on the basis of variation and effect of the atmosphere and emitting surface (Becker and Li 1990a; Sobrino et al 1996, 2003; Mao et al 2005).

It is widely documented that atmospheric transmittance, water vapour and surface emissivity generate significant impact on LST retrieval accuracy. Atmospheric transmittance describes the magnitude of attenuation of a radiance passing through the atmosphere. It is affected by a range

Keywords. Transmittance; emissivity; water vapour content. 


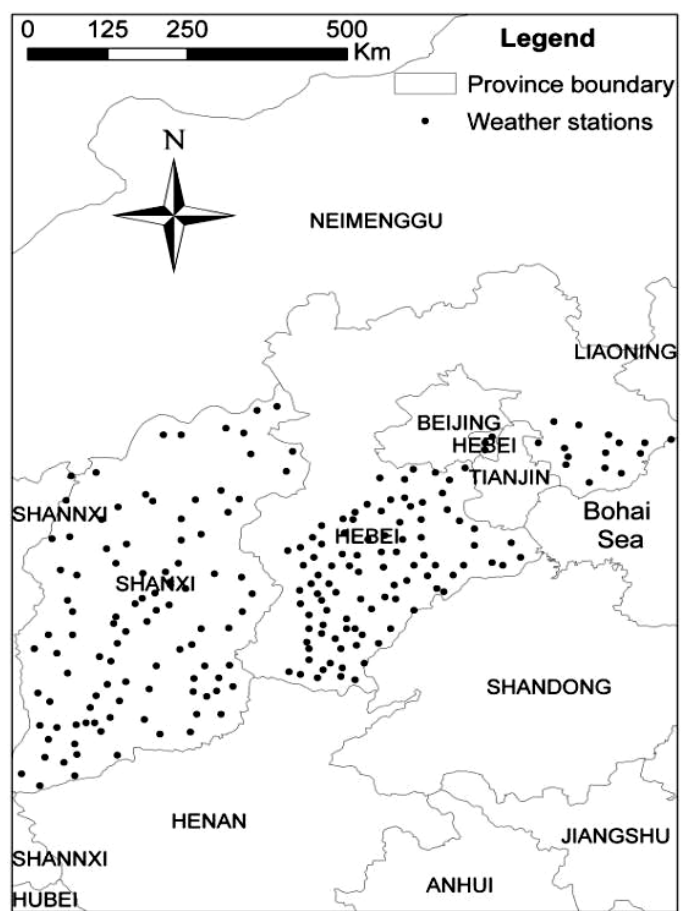

Figure 1. Location map of the study area.

of atmospheric constituents, including carbon dioxide, nitrogen oxide, ozone oxide, methane and other gases that are generally assumed fairly constant, as opposite to the highly variable water vapour content. Therefore variations in atmospheric transmittance strongly depend on the dynamics of water vapour content in the profile, especially for thermal channels. Among the 36 MODIS channels, channels $2(0.875 \mu \mathrm{m})$ and $5(1.24 \mu \mathrm{m})$ are atmosphere window bands, while channels $17(0.905 \mu \mathrm{m}), 18(0.936 \mu \mathrm{m})$ and 19 $(0.940 \mu \mathrm{m})$ are absorption bands. Thus, based on the characteristics of the channels, water vapour content of the atmosphere can be estimated directly from MODIS image, and transmittance will be further estimated. Considerable research work (Chesters et al 1983; Fraser and Kaufman 1985; Grant 1990; Kaufman and Gao 1992; King et al 1992; Czajkowski et al 2002) has been done in this regard.

Surface emissivity is a measure of inherent efficiency of the surface in converting heat energy into radiant energy above the surface (Sobrino et al 2001). It is critical for determining land surface thermal radiation (Caselles et al 1995), thereby, also a key parameter affecting LST retrieval accuracy through split-window algorithm. Already, many efforts have been made on surface emissivity estimation (Becker and Li 1990b; Li and Becker 1993; Van De Griend and Owe 1993; Valor and Caselles 1996; Wan and Li 1997; Gillespie et al 1998; Sobrino and Raissouni 2000; Sobrino et al 2001; Momeni and Saradjian 2007) using different techniques. Emissivity is often either assumed constant or estimated with empirical methods in split-window algorithms.

In this work, we have two objectives:

- to find out the effectiveness of two latest splitwindow methods for retrieving LST from AquaMODIS data by comparing their performance with LST product (as a standard), and

- to develop a simplified method from the two methods for LST estimation.

\section{Study area and data}

\subsection{Study area}

The study area covers mainly Hebei and Shanxi regions (figure 1), a representative area in North China Plain, which is a vital food production base of China. Each region contains agricultural weather stations with 113 and 101 station sites randomly distributed in Hebei and Shanxi regions respectively.

\subsection{MODIS data}

In this work, version 5 of Aqua-MODIS Level 1B products of daytime (MYD02 $1 \mathrm{~km}$ ), Land Surface Temperature and Emissivity (LST/E)-Daily L3 Global $1 \mathrm{~km}$ product (MYD11A1) on dates of $28 / 03,9 / 10$ and $14 / 11$ in 2006 were chosen randomly for little or no cloud atmosphere conditions. LST products downloaded with SIN projection in HDF format were then reprojected to Albers equal area projection with GeoTIFF format using MRT (MODIS Reprojection Tool), which is downloadable from 'http://lpdaac.usgs.gov/landdaac/ tools/modis/index.asp' website. LST products provide per-pixel temperature values with $1 \mathrm{~K}$ accuracy (Wan et al 2002).

\section{Methodology}

\subsection{Sobrino et al (2003) algorithm}

\subsubsection{Land surface temperature}

A quadratic algorithm for LST estimation is given as follows (Sobrino et al 2003):

$$
\begin{aligned}
T_{s}= & T_{31}+a_{1}+a_{2}\left(T_{31}-T_{32}\right)+a_{3}\left(T_{31}-T_{32}\right)^{2} \\
& +\left(a_{4}+a_{5} W\right)(1-\varepsilon)+\left(a_{6}+a_{7} W\right) \Delta \varepsilon
\end{aligned}
$$

where $T_{s}$ is land surface temperature; $T_{31}$ and $T_{32}$ represent brightness temperature of bands 31 and 
$32 ; a_{1}, a_{2}, a_{3}, a_{4}, a_{5}, a_{6}$ and $a_{7}$ are split-window coefficients acquired through simulation with values of $1.02,1.79,1.20,34.83,-0.68,-73.27$ and -5.19 respectively (Sobrino et al 2003); water vapour content of the atmosphere; $\varepsilon\left[\varepsilon=\left(\varepsilon_{31}+\varepsilon_{32}\right) / 2\right]$ is the mean effective emissivity of MODIS channels 31 and 32 ; and $\Delta \varepsilon\left(\Delta \varepsilon=\varepsilon_{31}-\varepsilon_{32}\right)$ is the spectral emissivity difference.

\subsubsection{Estimation of surface emissivity}

In the estimation of surface emissivity, NDVI (Normalized Difference Vegetation Index) threshold method (Sobrino et al 2001) is applied. Current soil characteristics in each pixel are taken into consideration according to the following procedures:

- Bare soil pixels: Values of NDVI lower than 0.2 are considered as bare soil (with vegetation proportion $P_{v}$ taken as zero, see below), which may include sparse vegetation or bare soil. According to MODIS channel 1 reflectivity $\left(\rho_{1}\right), \varepsilon$ and $\Delta \varepsilon$ are calculated as:

$$
\begin{gathered}
\text { NDVI }=\frac{\rho_{2}-\rho_{1}}{\rho_{2}+\rho_{1}}, \\
\varepsilon=0.9832-0.058 \rho_{1}, \\
\Delta \varepsilon=0.0018-0.060 \rho_{1},
\end{gathered}
$$

where $\rho_{1}$ and $\rho_{2}$ represent the reflectance value of MODIS bands 1 (RED) and 2 (NIR).

- Mixed pixels: When values of NDVI are between 0.2 and $0.5, \varepsilon$ and $\Delta \varepsilon$ are obtained as:

$$
\begin{aligned}
\varepsilon & =0.971+0.018 P_{v}, \\
\Delta \varepsilon & =-0.006\left(1-P_{v}\right),
\end{aligned}
$$

where $P_{v}$ is the vegetation fraction which can be derived according to Carlson and Ripley (1997), using NDVI image equation (5) below:

$$
P_{v}=\frac{\left(\mathrm{NDVI}-\mathrm{NDVI}_{\min }\right)^{2}}{\left(\mathrm{NDVI}_{\max }-\mathrm{NDVI}_{\min }\right)^{2}}
$$

- Vegetation pixels: Pixels with NDVI value higher than 0.05 are regarded as fully vegetated $\left(P_{v}=1\right)$ and thus $\varepsilon$ and $\Delta \varepsilon$ are restated as:

$$
\begin{aligned}
\varepsilon & =0.985+d \varepsilon, \\
\Delta \varepsilon & =0,
\end{aligned}
$$

with $d \varepsilon=0.005$.

\subsubsection{Estimation of water vapour content}

A 2-channel ratio of an absorption channel with a window channel is used to derive atmospheric transmittance of the absorption channel, and then total atmospheric water vapour content. With this method, as earlier mentioned in the introduction section, MODIS bands 2 and 5 are window channels and 17, 18 and 19 are absorption channels. However, the three absorption bands have different water vapour sensitivities under the same atmospheric condition. The strong absorption band 18 is most sensitive under dry conditions, while the weak absorption channel 17 is most sensitive under humid conditions (Kauman and Gao 1992). Therefore, the mean water vapour value $W$ can be obtained by the function described as (Sobrino et al 2003):

$$
W=0.192 W_{17}+0.453 W_{18}+0.355 W_{19},
$$

where $W$ is the total water content; $W_{i}(i=17,18$, and 19) is the water vapour value for MODIS channels 17, 18 and 19.

$$
\begin{gathered}
w_{17}=26.314-54.434 G_{17}+28.449 G_{17}^{2} \\
W_{18}=5.012-23.017 G_{18}+27.844 G_{18}^{2} \\
W_{19}=9.446-26.887 G_{19}+19.914 G_{19}^{2}
\end{gathered}
$$

$G_{i}\left(i=17,18\right.$, and 19) are ratios based on $L_{i}$ radiances, which are defined as:

$$
G_{i}=\frac{L_{i}}{L_{2}}
$$

For extreme conditions, the accuracy of this method gives a standard deviation of $0.17 \mathrm{~g} \mathrm{~cm}^{-2}$ for wet atmospheres $\left(3.32 \mathrm{~g} \mathrm{~cm}^{-2}\right)$ to $0.06 \mathrm{~g} \mathrm{~cm}^{-2}$ for dry atmospheres $\left(0.33 \mathrm{~g} \mathrm{~cm}^{-2}\right)$.

\subsection{Mao et al (2005) algorithm}

\subsubsection{Land surface temperature}

Mao et al (2005) introduced a split-window algorithm to retrieve LST from MODIS data. In their algorithm, land surface temperature $T_{s}$ is obtained from equation (10) as follows:

$$
T_{s}=\frac{\left(C_{32}\left(B_{31}+D_{31}\right)-C_{31}\left(B_{32}+D_{32}\right)\right)}{C_{32} A_{31}-C_{31} A_{32}},
$$


where $A_{31}, B_{31}, C_{31}, D_{31}$ and $A_{32}, B_{32}, C_{32}, D_{32}$ are functions of brightness temperature, emissivity or transmittance (also see Mao et al 2005). From the above equation, it appears difficult to find the relationship between LST and brightness temperature. In order to understand this relation further, equation (10) is simplified as follows:

$$
T_{s}=A_{0}+A_{1} T_{31}+A_{2} T_{32},
$$

$A_{0}, A_{1}$ and $A_{2}$ can then be calculated using the following formulas:

$$
A_{0}=\frac{\begin{array}{c}
{\left[0.09741 \cdot b_{31} b_{32}+229.61319 \cdot b_{32}\left(a_{31}-1\right)\right.} \\
\left.+223.6506 \cdot b_{31}\left(a_{32}-1\right)\right]
\end{array}}{a_{31} b_{32}-a_{32} b_{31}}
$$$$
A_{1}=\frac{b_{32}}{a_{31} b_{32}-a_{32} b_{31}}
$$$$
A_{2}=\frac{b_{31}}{a_{31} b_{32}-a_{32} b_{31}}
$$$$
a_{i}=\varepsilon_{i} \tau_{i}
$$$$
b_{i}=\left(1-\tau_{i}\right)\left(1+\left(1-\varepsilon_{i}\right) \tau_{i}\right)
$$

where $T_{i}, \varepsilon_{i}, \tau_{i},(i=$ bands 31,32$)$ are brightness temperature, emissivity and transmittance of band $i$ respectively, which can be calculated from the following sections. $a_{i}$ and $b_{i}(i=$ bands 31,32$)$ are intermediate variables defined in equations $(12 \mathrm{~d})$ and $(12 \mathrm{e})$.

Based on the simulation between water vapour content and the transmittance of bands 31 and 32 , the equations for MODIS 31/32 are as follows (Mao et al 2005):

$$
\begin{gathered}
\tau_{31}=2.89798-1.88366 e^{-(w /-21.22704)}, \\
\tau_{32}=-3.59289+4.60414 e^{w /-32.70639} .
\end{gathered}
$$

\subsubsection{Estimation of ground emissivity}

Emissivity is mainly dependent on land surface structure and the range of spectral band used. The average emissivity of three representative terrestrial land types is adopted. For band 31, the values of water, bare soil and vegetation are approximately $0.992,0.986$ and 0.972 , and for band 32 , the values are $0.988,0.991$ and 0.976 , respectively (Mao et al 2005). As far as mixed pixels, which normally constitute two or three components, estimation of ground emissivity is done as follows:

$$
\begin{aligned}
\varepsilon & =P_{v} R_{v} \varepsilon_{v}+\left(1-P_{v}-P_{w}\right) R_{s} \varepsilon_{s}, \\
P_{v} & =\frac{\mathrm{NDVI}-\mathrm{NDVI}_{s}}{\mathrm{NDVI}_{v}-\mathrm{NDVI}_{s}}
\end{aligned}
$$

where $P_{v}$ and $P_{w}$ represent vegetation and water fraction respectively, $P_{v}$ is estimated from equation (15) according to Kerr et al (1992); for $P_{w}$ calculation, if the pixel is water, then $P_{w}=1$, for the bank of ocean, $P_{w}=\mathrm{QDN} / \mathrm{DNI}, \mathrm{QDN}$ represents the reflectance of the pixel and DNI represents the least reflectance of the land pixel, which is attained by samples obtained from the image. $R_{v}$ and $R_{s}$ represent the radiance ratio of vegetation and soil, and are given as 0.966158 and 1.04359 respectively; $\mathrm{NDVI}_{v}$ and $\mathrm{NDVI}_{s}$ represent the NDVI of vegetation and bare soil, generally taken as 0.65 and 0.05 (Kerr et al 1992).

\subsubsection{Estimation of water content}

Because the atmospheric transmittance strongly depends on water vapour dynamics of the profile, and even more for thermal bands, it is retrieved based on water content using band ratio functions. In this work, bands 2 and 19 ratio was used and the relationship between the used ratio and transmittance obtained using Kauman and Gao (1992), $\tau_{w}$ (transmittance) can be calculated from MODIS image, then water vapour content can be calculated from:

$$
\begin{aligned}
& W=\left(\frac{0.02-\ln \tau_{w}}{0.651}\right)^{2}, \\
& \tau_{w}\left(\frac{19}{2}\right)=\frac{\rho_{19}}{\rho_{2}},
\end{aligned}
$$

where $\rho_{2}, \rho_{19}$ represent reflectance of bands 2 and 19 , respectively.

Kauman and Gao (1992) performed lots of experiments and analysis for different conditions and concluded that the accuracy of this method is within $13 \%$ in the cloud-free conditions.

\subsection{Calculation of brightness temperature}

For the inversion of LST with the two methods mentioned above, calculation of brightness temperature for MODIS bands 31 and 32 is required. In this work, brightness temperature was obtained 
from Planck radiation function according to Qin et al (2001):

$$
T_{i}=\frac{c_{2}}{\lambda \ln \left[1+\left(c_{1} / \lambda^{5} B_{\lambda}\left(T_{i}\right)\right)\right]},
$$

where $T_{i}(i=$ bands 31,32$)$ is brightness temperature; $\lambda$ is wavelength in meter; $c_{1}$ and $c_{2}$ are constants with $c_{1}=5.95522012 \times 10^{-17} \mathrm{~W} \mathrm{~m}^{-2}$ and $c_{2}=1.43876869 \times 10^{-2} \mathrm{~m} \mathrm{k} ; B_{\lambda}\left(T_{i}\right)$ is the spectral radiance, which can be acquired from MODIS L1B image.

\section{Results and discussion}

\subsection{Comparison of the two methods}

Preprocessing of the Aqua-MODIS L1B data for three days was performed, including the geolocations, bow-tie effect removal, image mosaicking, cloud masking, etc., with no topographic correction due to the location of the study area (plain landscape). The LST retrieval methods of Mao et al (2005) and Sobrino et al (2003) were then used to acquire LST maps of Hebei and Shanxi regions (figure 2). Due to difficulties in obtaining groundtruth measurements at the time of the satellite pass and the high accuracy of MODIS LST product, which has been proven to be within $1 \mathrm{~K}$ (Wan et al 2002), MODIS LST product was adopted as the standard for validation in place of groundtruth data. The evaluation of the methods was implemented in two steps:

1) comparison of statistical characteristics between retrieved LST maps and LST products, results of which are listed in table 1; and

2) verification by the standard LST product based on data from weather station sites.

In table 1, the max, min and mean values of estimated LST from the Mao method on the three dates are easily spotted as they are $1.33 \mathrm{~K}, 1.54 \mathrm{~K}$ and $0.13 \mathrm{~K}$ lower than the standard respectively. This is consistent with the findings of Mao et al (2005). On the contrary, the three indices of the Sobrino method are all higher than the standard, with average values of max error, min error and mean error of $0.73 \mathrm{~K}, 1.46 \mathrm{~K}$ and $1.50 \mathrm{~K}$, respectively. Through the comparison of the indices of two methods, it was noted that the absolute average values of max error and min error of the Sobrino method are less than those of the Mao method, whereas the average mean error of the Sobrino method is greater than that of the Mao method. It, however, appears difficult to evaluate which method is superior over the other for LST inversion only from the maps and table values; hence another statistical means was adopted for this purpose.

\subsection{Validation of the two methods}

In order to determine which method is better, the RMSE (Root Mean Square Error) was used to evaluate the accuracy of the two methods,

$$
\operatorname{RMSE}=\sqrt{\frac{\sum_{i=1}^{n}\left(O_{i}-R_{i}\right)^{2}}{n}},
$$

where $O_{i}$ and $R_{i}$ are observed and retrieved variables respectively and $n$ is the data number.

The validation results, based on LST products on the corresponding day of inversion LST, are shown in figure 3 . It needs to be mentioned that the number of weather stations for validation on each day differs $(84,104$ and 96 for three Julian dates, respectively), since sites with cloud effects were excluded in the validation and comparison analysis.

From the figure, it can be observed that two methods have little biases as can be found in the error bars. LST retrieved from Mao's method is generally lower than standard LST product, with a mean RMSE of $1.85 \mathrm{~K}$, whereas the Sobrino retrieved LST shows a good agreement with the standard, with a mean RMSE of $1.17 \mathrm{~K}$. The accuracy obtained from the current study is generally lower than that reported by Mao et al (2005) and Sobrino et al (2003), a probable short-fall of the use of LST product in place of measured ground truth data. In table 1, although the average mean error of the Sobrino method is higher than that of the Mao's, it is simply inadequate for a critical evaluation of the two methods. However, the analysis of RMSE and $R^{2}$ coefficients in figure 3 shows that the Sobrino method is superior over the Mao method for LST inversion.

\subsection{Sobmao methods}

Despite its higher accuracy of LST retrieval, the estimation of atmospheric water vapour content in the Sobrino method is generally complex, whereas the Mao algorithm is relatively simple. Water vapour estimation in the latter method needs only MODIS reflectance band 2 and absorption band 19 , while the former needs reflectance band 2 and absorption bands 17, 18 and 19 and, of course, more equations. Because the water vapour absorption ability of channel 19 is intervenient between the strong absorption channel 18 and the weak absorption channel 17, which are most sensitive to the dry and humid conditions, respectively, the band ratio of 19 to 2 can be applied over a wide range 

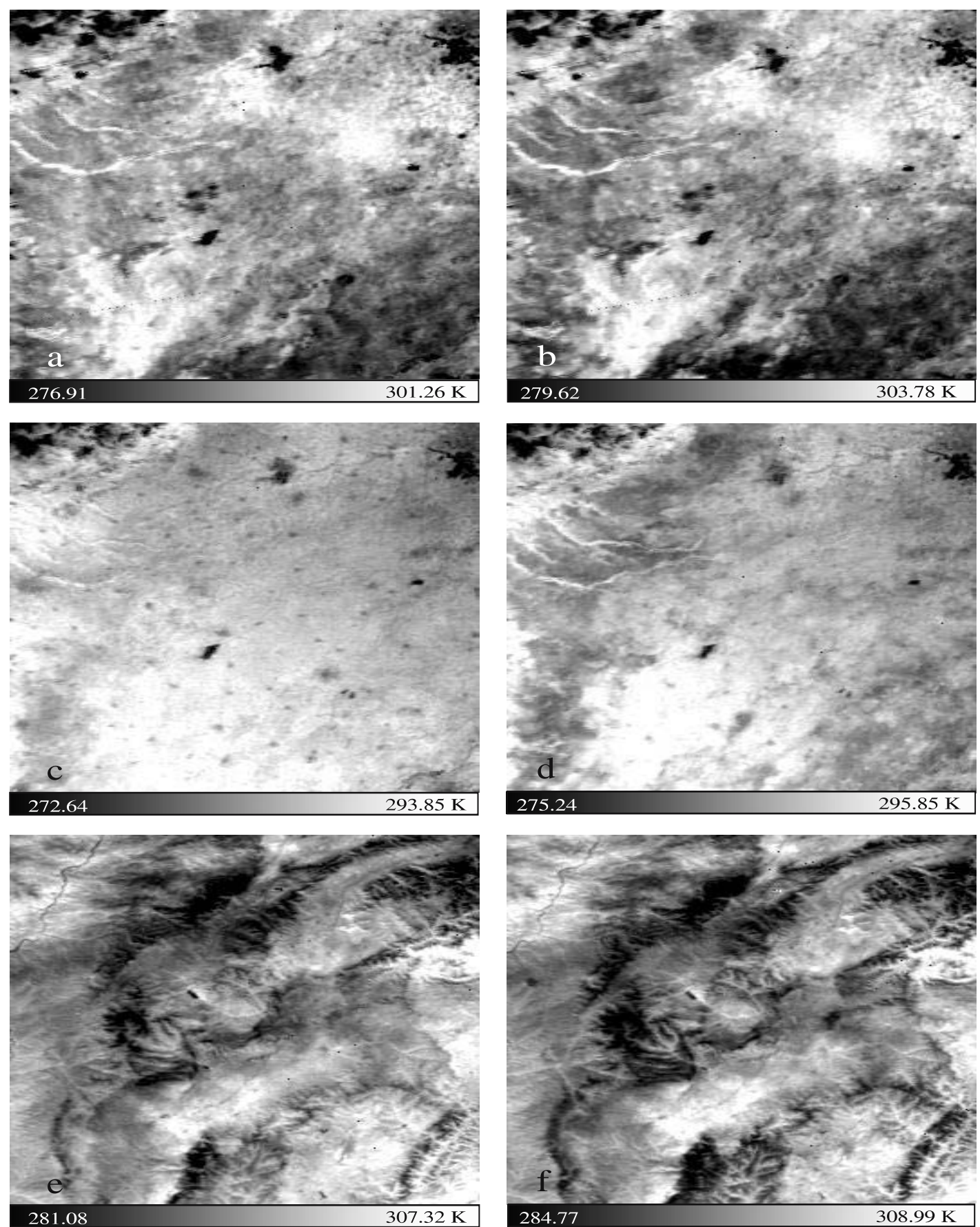

Figure 2. Map of retrieved LST on March 28, 2006 (a, b) and November 14, 2006 (c, d) in Hebei region; and October 9, $2006(\mathbf{e}, \mathbf{f})$ in Shanxi region ( $\mathrm{a}, \mathrm{c}$ and e for Mao method and b, $\mathrm{d}$ and $\mathrm{f}$ for Sobrino method).

of atmospheric conditions. For North China Plain, the annual average value of water vapour content is about $1.6 \mathrm{~g} \mathrm{~cm}^{-2}$, which is similar to the calculated result on date of October 9, 2006. Thereby it can be viewed as a combined use of the LST and emissivity estimation in the Sobrino method, and the water vapour content estimation in the Mao method, this method is code-named Sobmao, with an LST retrieval value hardly different from that of the Sobrino method. In other words, the statistical characteristics, inversion map of LST distribution and validation RMSE are almost the same as the Sobrino method. Its max, min and mean statistical values of inversion map of LST are listed also in table 1 , while the validation results are plotted in figure 3. Being that it has the same accuracy and a much simplified water vapour content estimation, Sobmao method is recommended for retrieval of LST. Since Sobrino and Sobmao have different methods for estimation of water vapour 
Table 1. Statistical characteristics of retrieval LST (Mao and Sobrino method) and LST product.

\begin{tabular}{llcccccc}
\hline $\begin{array}{l}\text { Date } \\
(\mathrm{dd} / \mathrm{mm} / \mathrm{yy})\end{array}$ & Method & Max $(\mathrm{K})$ & Error $(\mathrm{K})$ & Min $(\mathrm{K})$ & Error $(\mathrm{K})$ & Mean $(\mathrm{K})$ & Error $(\mathrm{K})$ \\
\hline $28 / 03 / 06$ & LST & 302.84 & - & 277.90 & - & 295.02 & - \\
(in Hebei) & Mao & 301.26 & -1.58 & 276.91 & -0.99 & 294.95 & -0.07 \\
& Sobrino & 303.78 & 0.94 & 279.62 & 1.72 & 296.91 & 1.89 \\
& Sobmao & 303.79 & 0.95 & 279.63 & 1.73 & 296.91 & 1.89 \\
14/11/06 & LST & 295.54 & - & 274.68 & - & 289.19 & - \\
(in Hebei) & Mao & 293.85 & -1.69 & 272.64 & -2.04 & 289.03 & -0.16 \\
& Sobrino & 295.85 & 0.31 & 275.24 & 0.56 & 290.49 & 1.30 \\
& Sobmao & 295.86 & 0.32 & 275.26 & 0.58 & 290.49 & 1.31 \\
09/10/06 & LST & 308.04 & - & 282.67 & - & 297.46 & - \\
(in Shanxi) & Mao & 307.32 & -0.72 & 281.08 & -1.59 & 297.3 & -0.16 \\
& Sobrino & 308.99 & 0.95 & 284.77 & 2.1 & 298.78 & 1.32 \\
& Sobmao & 308.99 & 0.95 & 284.78 & 2.2 & 298.79 & 1.33 \\
\hline
\end{tabular}
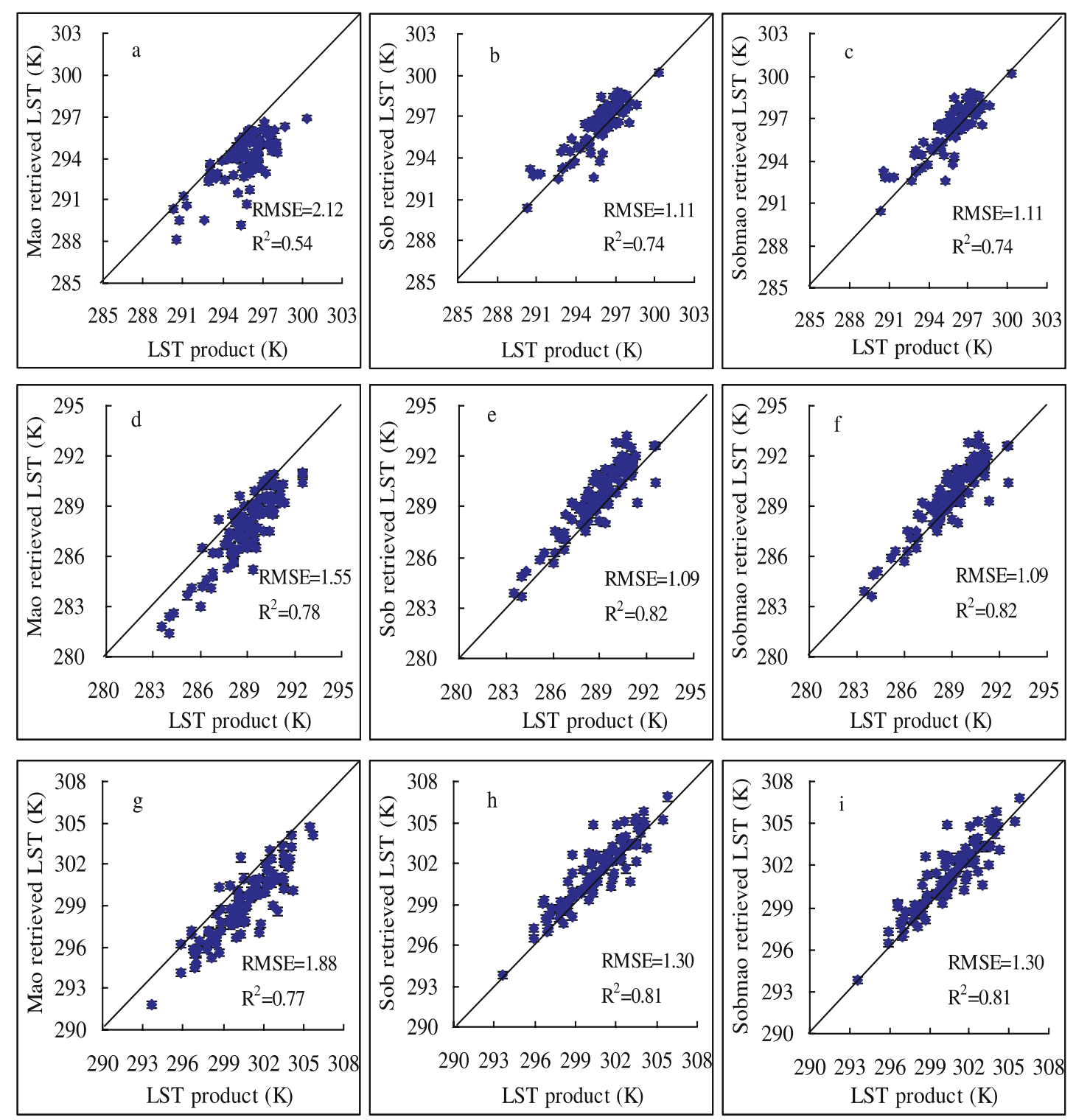

Figure 3. Match between retrieved and LST product for March 28, 2006 (a, b, c) and November 14, 2006 (d, e, f) in Hebei region and October 9, $2006(\mathbf{g}, \mathbf{h}, \mathbf{i})$ in Shanxi region. 

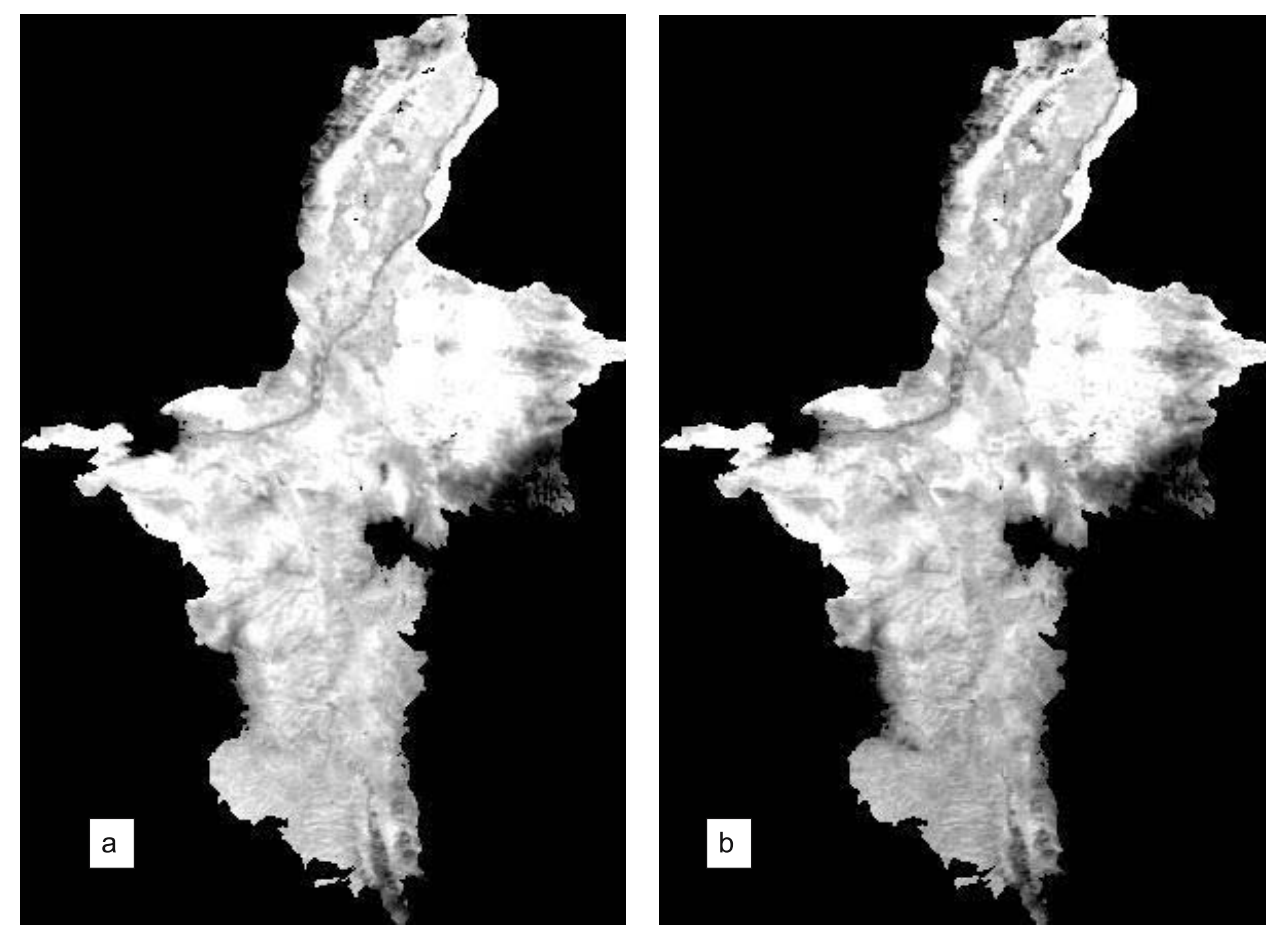

Figure 4. LST maps of (a) Sobmao method and (b) LST product on September 30, 2008 in Ningxia region.

content but same accuracy of LST, it is suggested that water vapour content is not sensitive to the split-window algorithm, which can be derived from the split-window equation. This is also consistent with Mao et al (2008).

In order to test the reliability, Sobmao method is applied in a different region, Ningxia Huizu Autonomous Region in northwest China. Data used include version 5 of Terra-MODIS Level 1B products of daytime (MOD02 $1 \mathrm{~km}$ ) and Land Surface Temperature and Emissivity (LST/E)-Daily L3 Global $1 \mathrm{~km}$ product (MOD11A1) on date of $30 / 09 / 2008$. Image is preprocessed similar with the description in section 4.1, and two maps of the Sobmao retrieved LST and the MODIS standard LST product are shown in figure 4 . The results of two LST maps are very similar, and the Sobmao method's LST values of max, min and mean are $304.21 \mathrm{~K}, 283.93 \mathrm{~K}$ and $296.13 \mathrm{~K}$ respectively, the LST product's values of max, min and mean are $304.54 \mathrm{~K}, 285.43 \mathrm{~K}$ and $295.80 \mathrm{~K}$ respectively. Thus, the differences between Sobmao method's LST values of max, min and mean and the LST product's are only $0.33 \mathrm{~K}, 1.50 \mathrm{~K}$ and $0.33 \mathrm{~K}$ respectively. Using the LST product as standard, RMSE of Sobmao is calculated. An RMSE value of $0.91 \mathrm{~K}$ indicates the reliability of the newly developed Sobmao method. It should be noted that the application of LST retrieval approach is better in arid northwest China region than in semi-humid north China. Therefore, this method may be more applicable in arid regions.

\section{Conclusions}

Mao et al (2005) and Sobrino et al (2003) methods were used to retrieve LST from MODIS data (on three different dates) in Hebei and Shanxi regions. Through comparing the results of the two methods with MODIS LST product, the Sobrino method has been proved to be more accurate for retrieving LST, with RMSE of $1.17 \mathrm{~K}$, irrespective of a higherthan-standard average mean error compared with the Mao method. Finally, the Sobmao method is recommended for retrieving LST because of its high accuracy, simplified estimation of atmospheric water vapour content, and its reliability for application in Ningxia region, the arid northwest China, with the mean error of $0.33 \mathrm{~K}$ and the RMSE value of $0.91 \mathrm{~K}$.

Although MODIS data for several cloud-free days are selected randomly, it is still hard to conclude that the results can represent the whole year. More reliable comparison with much longer time series data shall be necessary.

\section{Acknowledgements}

The authors appreciate the financial support of the National Natural Science Foundation of China (40771148 and 40771037), R\&D Special Fund for Public Welfare Industry of China (Meteorology): (GYHY200806022) and the Key Innovation Project in the field of Environment and Resources, 
the Chines Academy of Sciences (KZCX1-YW-0803-04). We are also grateful that LP DAAC, USGS provided MODIS data. Finally, we also thank the fruitful comments by Dr Moiwo Juana Paul, the editors and anonymous reviewers.

\section{References}

Becker F and Li Z 1990a Towards a local split window method over land surface; Int. J. Remote Sens. 11 369-394.

Becker F and Li Z 1990b Temperature-independent spectral indices in TIR bands; Remote Sens. Environ. 32 $17-33$.

Carlson T N and Ripley D A 1997 On the relation between NDVI, fractional vegetation cover, and leaf area index; Remote Sens. Environ. 62 241-252.

Caselles V, Coll C, Valor E and Rubio E 1995 Mapping land surface emissivity using AVHRR data: Application to La Mancha, Spain; Remote Sens. Rev. 12 311-330.

Chesters D, Ucellini W and Robinson W D 1983 Low level water vapor fields from the VISSR Atmospheric Sounder (VAS) "Split Window" Channels; J. Clim. Appl. Meteorol. 22 725-743.

Coll C, Caselles V, Galve J M, Valor E, Niclòs R, Sánchez J M and Rivas R 2005 Ground measurements for the validation of land surface temperatures derived from AATSR and MODIS data; Remote Sens. Environ. $97288-300$.

Czajkowski K P, Goward S N, Shirey D and Walz A 2002 Thermal remote sensing of near-surface water vapor; Remote Sens. Environ. 32 17-33.

Diak G R and Whipple M S 1993 Improvements to models and methods for evaluating the land-surface energy balance and effective roughness using radiosonde reports and satellite-measured skin temperature data; Agri. Forest Meteorol. 63(3-4) 189-218.

Fraser R S and Kaufman Y 1985 The relative importance of scattering and absorption in remote sensing; IEEE Trans. Geosci. Remote Sens. 23 625-633.

Gillespie A R, Rokugawa S, Matsunaga T, Cothern J S, Hook S J and Kahle A B 1998 A temperature and emissivity separation algorithm for advanced space borne thermal emission and reflection radiometer (ASTER) images; IEEE Trans. Geosci. Remote Sens. 36 1113-1126.

Grant W B 1990 Water vapor absorption coefficient in the 8-13- $\mu$ m spectral region: A critical review; Appl. Opti. 29 451-462.

Kaufman Y J and Gao B C 1992 Remote Sensing of Water Vapor in the Near IR from EOS/MODIS; IEEE Trans. Geosci. Remote Sens. 30(5) 871-884.

Kerr Y H, Lagouarde J P and Imbernon J 1992 Accurate land surface temperature retrieval from AVHRR data with use of an improved split window algorithm; Remote Sens. Environ. 41 197-209.

King M D, Kaufman Y J, Menzel W P and Tanri D 1992 Remote sensing of cloud, aerosol and water vapour properties from the Moderate Resolution Imaging Spectrometer (MODIS); IEEE Trans. Geosci. Remote Sens. 30 2-27.

Li Z and Becker F 1993 Feasibility of land surface temperature and emissivity determination from AVHRR data; Remote Sens. Environ. 43 67-85.

Mao K, Qin Z, Shi J and Gong P 2005 A practical splitwindow algorithm for retrieving land surface temperature from MODIS data; Int. J. Remote Sens. 26(10) $3181-3204$.

Mao K, Tang H, Zhou Q and Ma Z 2008 Improvement for the split window algorithm and influence analysis of water vapor content for retrieval accuracy; Geomatics and Information Science of Wuhan University 33(2) 116-119 (in Chinese Abstract).

Momeni M and Saradjian M R 2007 Evaluating NDVIBased Emissivities of MODIS Bands 31 and 32 Using Emissivities Derived by Day/Night LST Algorithm; Remote Sens. Environ. 106 190-198.

Price J C 1982 On the use of satellite data to infer surface fluxes at meteorological scales; J. Appl. Meteorol. 21 $1111-1122$.

Qin Z, Dall'Olmo G, Karnieli A and Berliner P 2001 Derivation of split window algorithm and its sensitivity analysis for retrieving land surface temperature from NOAA-advanced very high resolution radiometer data; J. Geophys. Res. 106 22,655-22,670.

Sobrino J A, Caselles V and Becker F 1990 Significance of the remotely sensed thermal infrared measurements obtained over a citrus orchard; ISPRS Photogrammetric Engineer. Remote Sens. 44 343-354.

Sobrino J A, Li Z, Stroll M P and Becker F 1996 Multichannel and multi-angle algorithm for estimating sea and land surface temperature from ATSR data; Int. J. Remote Sens. 17 2089-2114.

Sobrino J A and Raissouni N 2000 Toward remote sensing methods for land cover dynamic monitoring: Application to Morocco; Int. J. Remote Sens. 21 353-366.

Sobrino J A, Raissouni N and Li Z 2001 A comparative study of land surface emissivity retrieval from NOAA data; Remote Sens. Environ. 75 256-266.

Sobrino J A, El-Kharraz J and Li Z 2003 Surface temperature and water vapour retrieval from MODIS data; Int. J. Remote Sens. 24(24) 5161-5182.

Valor E and Caselles V 1996 Mapping land surface emissivity from NDVI: Application to European, African, and South American areas; Remote Sens. Environ. 57 $167-184$

Van De Griend A A and Owe M 1993 On the relationship between thermal emissivity and the normalized difference vegetation index for natural surfaces; Int. J. Remote Sens. 14(6) 1119-1131.

Wan Z and Li Z 1997 A physics-based algorithm for retrieving land surface emissivity and temperature from EOS/MODIS data; IEEE Trans. Geosci. Remote Sens. 35 980-996.

Wan Z, Zhang Y, Zhang Q and Li Z 2002 Validation of the land-surface temperature products retrieved from Terra Moderate Resolution Imaging Spectroradiometer data; Remote Sens. Environ. 83 163-180. 